\title{
EVALUATION OF BRAND COMPETITIVENESS: REGRESSION ANALYSIS APPROACH
} Mindaugas Butkus ${ }^{1}$, Riccardo Masullo ${ }^{2}$

\author{
${ }^{1}$ Business Management Faculty, Department of Business Technologies, Sauletekio al. 11, Vilnius, Lithuania \\ ${ }^{2}$ Department of Industrial Engineering, School of Engineering and Architecture, University of Bologna, \\ Viale Risorgimento 2, Bologna, Italy \\ E-mails: ${ }^{1}$ mindaugas.butkus@vgtu.lt (correspondingauthor); ${ }^{2}$ riccardo.masullo@gmail.com
}

\begin{abstract}
Article aims to show an application of regression analysis for qualitative evaluation of companies' brand competitiveness from a customer point of view. Presented methodology could be applied if only a certain level of competition is observed in the market. We assume that (i) brand competitiveness is embodied into commodities', that companies are selling, prices and (ii) companies that have more competitive brand are able to sell their commodity at a higher price after controlling for other explicit factors potentially affecting price. For this purpose, we adapt classical linear regression model and provide an example with car companies' brands in the Italian market.
\end{abstract}

Keywords: commodity market, implicit brand, brand competitiveness, regression analysis, explicit properties.

JEL Classification: C51; M30.

\section{Introduction}

The importance and relevance of brands to economies in the twenty-first century is underscored by the fact that brands are now one of the most valuable assets to companies. In line with this increased recognition of the significance of brands, the literature on branding has grown proportionately in the last couple of decades. New concepts and new measures of ideas have being developed to enable us to understand and to evaluate brands in today's world. With this growth, our understanding of the branding process now includes its development, nurture, evaluation and maintenance - all of which enhance the longevity of a brand and the competitiveness of it. Brand include (but are not limited to) the Reputation and the Identity of the companies. Customers create a brand-based view of companies, and it is through these that they develop their perceptions of, and perspectives on, the identity of companies. But brand name alone does not make a brand. Developing market-leading brand capacities is essential for long-term competitiveness. This, however, requires more than just brand communications. The ability of brands to facilitate organisations' development, evolution and competitive advantage epitomizes the emerging role of brand strategy as an underlying resource that enables a firm to create, deliver and capture values faster than they can be competed away.
In this research we assume that companies that have stronger (more competitive) brand are able to sell their commodity at a higher price after controlling for other explicit factors potentially affecting price. We analyze brand competitiveness from customers' point of view as market price of a commodity represent customers' willingness to pay certain price for a certain brand after comparing alternative competing commodities and their explicit properties. Thus presented methodology could be applied if only a certain level of competition is observed in the market.

The aim of the article is to apply regression analysis methodology for testing empirically the consumer evaluation of brand competitiveness. The results of this research might be useful to academicians in area of brand marketing, for companies trying to justify spending on brand promotion, and other applied researchers.

Thus, the rest of the paper proceeds as follows: Section 2 presents the literature review of the brand concept, determinants of brand competitiveness, and the methods commonly used for empirical evaluation of brand competitiveness; adoption of regression analysis methodology for empirical evaluation of brand competitiveness is described in Section 3; Section 4 discusses the results of method application in Italian car market; finally, Section 5 closes the paper with the main conclusions. 


\section{Brand competitiveness: theoretical framework}

According to Jeff Bezos, founder and CEO of Amazon "Your brand is what people say about you when you're not in the room". "In one sense, perhaps the most important sense, a brand is a promise. [...] Buying a certain brand says something about the person who buys it" (Geller 2012). From this quotes it is clear that the brand is something more than just a name, a term or a symbol that represents a company. It is "a product or service whose dimensions differentiate it in some way from other products or services designed to satisfy the same need" (Kotler, Keller 1967). Using different words brand is the identity of a company as it is felt from the customers and it depends on the products and services and their emotional value. That's why "brand building has become the key to development of enterprises under the situation of products becoming more and more homogeneity" (Li et al. 2013). There is the need to increase the difference between my product and the ones from the competitors and to create our own image in order to gain competitive advantage. This is what we call branding. "Branding is the art of aligning what you want people to think about your company with what people actually do think about your company" (Baer, Naslund 2011). In brief "branding is endowing products and services with the power of a brand" (Kotler, Keller 1967).

From this viewpoint it shouldn't be surprising that "brand competitiveness determines core competitiveness of enterprises and becomes the driving force of enterprise development" (Li et al. 2013). A brand is competitive if it offers products and services that meet customer's needs and quality standards at a price that can compete with the other products on the market. This is also related to brand's image that influence how people think, feel and act regard the brand. Moreover, a brand to be competitive has to guarantee returns to the stakeholders (profitability). This is only possible if you have "in-depth knowledge of your target, your competitors, and your own business" and if you "use rigorous market research and competitive intelligence to uncover new insights and develop a proprietary point of view about the market opportunities and competitive landscape" (Yohn 2011). It is therefore really important to know the environment and his actors in order to define our brand equity.

"Brand equity is the added value endowed on products and services" (Kotler, Keller 1967). The advertising agency Young \& Rubicam created the
"Brand Asset Valuator (BAV) model" to evaluate the brand equity and his evolution. This model considers two variables: brand strength (the grow potential of a brand) and brand stature (the brand's current power). The first characteristic is explained as the sum of differentiation and relevance and the second one is described as the union of esteem and knowledge. By using this model, it is possible to define the current situation of a brand and thus to decide how to increase his value. In this model a four-quarter chart is set and from this chart we can evaluate if a brand is a "power brand", an "aspiring brand", a "fading brand" or an "eroding brand" (Mizik, Jacobson 2008).

Other example of models for brand equity are BrandZ from Millward Brown (Nigel 2005), WPP based on the Brand Dynamics Pyramid divided into 5 levels: presence, relevance, performance, advantage, and bonding (Uggla 2014) and Aaker model from Barkley marketing professor David Aaker that describe brand equity as a set of 5 categories: loyalty, awareness, quality, association and other assets (Huang, Cai 2015)

In the study by Saji et al. (2012) it is used an integrated approach to evaluate the brand competitiveness indicators related with drivers. This method, for instance, consider both financial and nonfinancial performances as competitiveness indicators and both external drivers and internal ones. Using an Analytic Hierarchy Process (AHP) it is possible to evaluate the most important indicators and drivers and to create a competitiveness assessment method (Sirikrai, Tang 2006). Focusing on the indicators, as we already said, there are both financial indicators such as ROI, ROA and nonfinancial ones for instance overall customer satisfaction, market share and his growth, overall competitiveness, sales volume and sales growth and overall plant success and productivity.

The AHP is often used to evaluate brand competitiveness. In a research from Biaowen (2014) for example a multi-index method is used to evaluate the brand competitiveness in the web 2.0 environments and the weight of each factor is set using the AHP. The first level features considered are: Market Capacity, Management Ability, Development Potential, Relationship and Website construction each divided into several second level features.

In another study by Zhang et al. (2015) it is used a similar approach. First of all, authors develop a literature review and an expert interview trying build a basic framework for the project than the weight of the attributes, divided into two levels, are evaluated using the AHP. After the consistency test 
the model can be used to evaluate the competitiveness of the company's brands. The first level indicators used are: enterprises infrastructure resource, brand management, customers' support and market competitiveness.

These are just few examples of models that have been developed to try to evaluate brand competitiveness by taking into account several aspects. However according to Coates et al. (2002) and Hoskisson at al. (1999), there is still debate among several disciplines regarding how the firms' brand competitiveness should be measured and what factors affect competitive performance. These divergent perspectives suggest to search for an alternative approach that would apply multiple theories to analyse competitiveness in order to better appreciate its complexity.

Although each field is different and it is really important to choose method that best fit the sector, after this literature overview we can outline a few shortages which we think overcomes our proposed firms brand competitiveness evaluation method:

- Most of commonly used methods rely on subjective expert view about components of brand competitiveness. We also assume that brand and its competitiveness should be analyzed using multidimensional approach, but more objective analysis can be performed using market based, but not expert based, view.

- Second drawback is related with a view that companies' investment in a brand by promoting it, tighten relationships with customers, developing companies' internal management abilities and etc. strengthen brand competitiveness. From our point of view brand competitiveness consists not of inputs but of outputs and thus results of those investments but not investments by themselves can be a measure of brand competitiveness.

- Vast majority of brand competitiveness evaluation models requires data (about customers' satisfaction, loyalty, awareness, association, etc.) that can be hard or quite costly to collect. We would like to underline that while evaluating the model it is essential to consider if the indicators can be easily evaluated and if we have the possibility to get data about them. According to Wang, Jiang (2008) many indicators in researches from this field can hardly be evaluated accurately, but can be estimated roughly, studied by qualitative analysis and escribed by semi-quantitative catego- rizing. Our proposed method does not deviate from customer's approach but partly overcomes this problem because data can be easily collected and do not requires subjective valuation. We adopt Kotler and Keller (1967) point of view to this problem "In order to quantitative evaluate each indicator we can use two different approaches: we can conduct an audit asking the customers how they evaluate the brand or we can collect data about the brand by studying how it is performing".

- Forth and last one - the proposed method evaluates company's brand competitiveness not isolated but along with other companies. In this way the method is constructed in more generalized way and thus it is suitable not just for a particular company but for all the companies in particular sector and with minimal adjustments can be applied to companies in other sectors.

\section{Methodology}

As a part of this research aim is to demonstrate how classical multiple linear regression model could be adopted for empirical estimation of brand competitiveness from customer's perspective. Generalisation of our idea is presented in Figure 1.

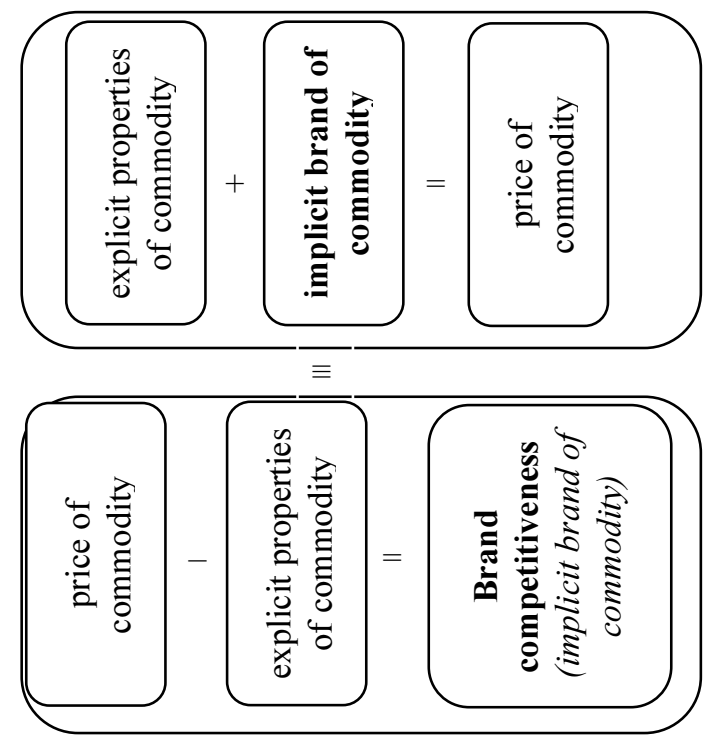

Fig. 1. Generalization of brand competitiveness empirical estimation idea (Source: created by the authors)

Upper part of Figure 1 represents simplified idea that from customers' point of view their willingness to pay for a certain commodity depends on two factors: explicit properties of a commodity that 
can be compared in the market of certain commodity and implicit brand of a company. In the lower part of Figure 1 we rearrange the equations in such a way that it would be equivalent to the one in the upper part but expresses implicit value of a company's brand in terms of difference between price of commodity and explicit properties of a commodity.

This simplified model for estimation of brand competitiveness takes into the account only demand side factors in price formation process (explicit properties of commodity). In this model we assume that supply side factors in price formation process are secular and do not vary in certain market thus these are not specific for a particular commodity or a also particular brand.

In the next step we present our idea in a more formal and thus suitable for empirical application regression form. For the basis we take classical multiple regression equation:

$$
P_{i}=\alpha+\sum_{j=i}^{m} \beta_{j} \cdot e p_{i j}+u_{i},
$$

where: $P_{i}$ - price of the i-th commodity; $\alpha-$ is a constant (intercept); $\beta_{j}-$ is an $\mathrm{j}$-th slope coefficient representing impact of a certain explicit property of a commodity on a price; $e p_{i}-$ is $\mathrm{j}$-th explicit property of i-th commodity (model can handle both quantitative and qualitative properties of a commodity); $u_{i}-$ is an error term.

Equation (1) in formal way describes upper part of Figure 1.

$$
\sum_{j=i}^{m} \beta_{j} \cdot e p_{i j},
$$

represents part of price for which explicit properties of a commodity account for and $u_{i}$ - implicit brand of a company, the part of the price that is not captured by the model which includes only explicit properties of a commodity.

Having a certain sample and using common techniques we can estimate the model and thus calculate error terms using an equation:

$$
\hat{u}_{i}=P_{i}-\hat{\alpha}-\sum_{j=i}^{m} \hat{\beta}_{j} \cdot e p_{i j},
$$

which represents lower part of Figure 1. We should note here that the sample must contain at least few of commodities representing particular brand, because we are estimating the competitiveness of a particular brand and not the competitiveness of a particular commodity. Once we have expres- sion (3) - comparison of actual market price with the forecasted one - we can estimate the level of competitiveness of the brand. If the sum of actual (observed) prices of commodities within certain brand will be lower than the sum of forecasted prices:

$$
\left(\sum_{i=1}^{n} \hat{u}_{i}=\sum_{i=1}^{n}\left(P_{i}-\hat{P}_{i}\right)\right)<0,
$$

it would be reasonable to say that the level of competitiveness of the company brand is low. It would be reasonable to compare not only these sums but rather weighted averages because we can have cases where companies can sell lots of commodities at lower than estimated prices but joint share of the market can be small compared to just one commodity sold at higher price than estimated one. So after the adjustments it would be reasonable to say that the level of competitiveness of the company brand is low if:

$$
\left(\sum_{i=1}^{n} \hat{u}_{i} \cdot w_{i}=\sum_{i=1}^{n}\left(P_{i}-\hat{P}_{i}\right) \cdot w_{i}\right)<0,
$$

where $w_{i}$ - represents the weight, calculated as a share of the certain commodity in particular market. Vice versa if the weighted averages of observed price of commodities within certain brand is higher than the forecasted price we can say that the competitive advantage created by the company is high, as follows:

$$
\left(\sum_{i=1}^{n} \hat{u}_{i} \cdot w_{i}=\sum_{i=1}^{n}\left(P_{i}-\hat{P}_{i}\right) \cdot w_{i}\right)>0 .
$$

We also want to note here, that we should interpret values of estimated positive/negative difference as an indicator of high/low brand competitiveness in quantitative way with caution. This approach is more suitable for qualitative evaluation. A tool created in this way can be also used by companies during the research and development stage in order to forecast the price of a new commodities.

We will end this part with brief overview of properties that error term of the model must satisfy to produce best linear unbiased estimators (BLUE) for statistically reliable analysis results and suggestions for adjustments if needed. First of all, it is necessary to test assumption of linearity (relationship between price and explicit properties of a commodity must have linear form). Harrell (2015) in his book about nonlinearity detection and correction in regression models suggests to use La- 
grange multiplier (LM) test statistics. If the model contains nonlinear relationships, we can use log transformation of the data or model nonlinear relationships using squares of variables along with initial ones. Second step is to test normality of the residuals. For that Razali and Wah (2011) propose to use Chi-square $\left(\chi^{2}\right)$ test. In case of concluding that residuals are not normally distributed, we can use common approaches like leverage or Cook's distance and etc. proposed by Adikaram et al. (2014) to detect outliers and eliminate them from a sample. Third step is to test, using White's proposed approach (Waldman 1983), for constant variation of residuals. Heteroskedastic variation can be eliminated using weighted least squares estimation or other techniques explained in details by Kaufman (2013). Last step is to test the presence of multicolinearity between two or more independent variables using variance inflation factor (VIF) or other method proposed by Mansfield and Helms (1982). In a case of a strong multicolinearity we suggest to use techniques explained by Kumari (2008) in similar research area. According to Cameron et al. (1997) adjusted $\mathrm{R}^{2}$ we will use to identify which part of price variation is explained by the explicit properties of commodity included in the model, thus $\left(1-\mathrm{R}^{2}\right)$ will be interpreted as a part of price variation for which implicit brand of a company accounts for.

\section{Application of research methodology and discussion}

In this section we will show an application example of the proposed method for empirical estimation of brand competitiveness using the Italian car market. To do this we will follow further steps: (i) identify main explicit properties of cars that are important for customers in Italy and thus influence price of a car; (ii) present collected sample for the analysis; (iii) run the analysis using presented method and finally (iv) conclude obtained results.

In our analysis we are going to consider as a dependent variable the average price of the different versions of the same car model (variable price). Regarding the explicit properties of a car we are going to use both quantitative properties and qualitative ones, by converting them in binary variables called "dummy". The quantitative are:

- Engine power in $\mathrm{cm}^{3}$ (variable engine).

- Number of versions of the model (variable vers).

- Average combined fuel consumption in litres per $100 \mathrm{~km}$ (variable fcon).

- Maximum speed in $\mathrm{km} / \mathrm{h}$ (variable speed).
The qualitative are:

- Car type (according to the Italian category subdivision from $A$ to $F$ ).

- Nationality of the brand (Italian or foreigner).

- Age of the model in years.

- Number of different possible engine fuel (gasoline only, both gasoline and diesel or gasoline and diesel and LPG).

We transform the qualitative variables into binary values using dummy variables. We need to transform car type, nationality of the brand, age and number of engine.

The variable car type can have $z=4$ alphabetic values "A, B, C, D“. Type A cars are city cars, the Type B segment represents small cars, Type $C$ group represents medium size cars and Type D represents medium-big size cars. We have to create $z-1=3$ binary dummy variables. Car type $\mathrm{D}$ will be our benchmark group and A, B, C will be dummy variables.

- $A=1$ if the car is type $A, A=0$ otherwise.

- $B=1$ if the car is type $B, B=0$ otherwise.

- $\mathrm{C}=1$ if the car is type $\mathrm{C}, \mathrm{C}=0$ otherwise.

Regarding the variable nationality, we would like to compare prices of Italian cars with the foreigner ones. So we are using just one dummy variable called ITA.

- ITA $=1$ if the brand is Italian.

- ITA $=0$ if the brand is German, French, American or from other countries.

Speaking about age we will use just one dummy variable called NEW.

- NEW $=1$ if the car model is 1 -year-old.

- NEW $=0$ if the car model is 2 or 3 years old.

- At the end we set a variable for the number of possible engine fuel.

- MULTIFUEL $=1$ if the car is produced with more than one engine fuel.

- MULTIFUEL $=0$ if the car is only produced with the gasoline engine.

We can ground importance of these explicit properties of a car to a customer and thus for a price by showing what is the impact that each characteristics have on the price. Reasonable we can think that cars of medium-high dimensions will be more expansive (engine power, maximum speed, car type) as well as older car models will be less expensive than newest ones (age of the mod$e l$ ). We are hypothesizing also that the number of different versions could influence the quality perception of customers and so it could determine a higher price as well as the number of different possible engine fuel. It is not easy to justify what im- 
pact could have the combined fuel consumption on the car price because it seems reasonable to think that the customer should prefer a less consuming car but, on the other hand, the fuel consumption is strictly related to the engine and car size. Finally, we think that Italian people prefer Italian cars in other words they discriminate foreign brands in favour of domestic ones.

Our sample is composed from the 50 bestselling cars in Italy in 2014. This sample is particularly suitable because it represents more than 73\% of the population (the total number of cars sold). Our data comes from the website quattroruote.it, this is the most important cars catalogue in Italy. There we can find the actual prices for each model and the official characteristics declared. Our sample in generalized form is presented in Table 1.

Table 1. Properties or research sample

(Source: created by the authors)

\begin{tabular}{|c|c|c|c|c|c|}
\hline 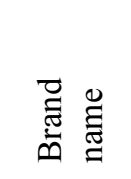 & 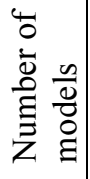 & 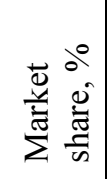 & 胥 & 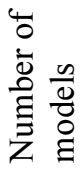 & 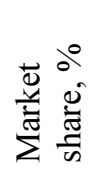 \\
\hline $\begin{array}{r}\text { Alfa } \\
\text { Romeo }\end{array}$ & 2 & 1.93 & Lancia & 1 & 3.54 \\
\hline Audi & 3 & 2.19 & $\begin{array}{r}\text { Mercedes } \\
\text { Benz } \\
\end{array}$ & 3 & 1.98 \\
\hline BMW & 1 & 0.63 & Mini & 1 & 1.40 \\
\hline Citroen & 1 & 1.78 & Nissan & 2 & 2.29 \\
\hline Dacia & 2 & 2.42 & Opel & 3 & 3.92 \\
\hline Fiat & 6 & 19.97 & Peugeot & 3 & 4.20 \\
\hline Ford & 5 & 5.58 & Renault & 3 & 4.86 \\
\hline Hyundai & 2 & 1.35 & Smart & 2 & 1.65 \\
\hline Jeep & 1 & 1.47 & Toyota & 3 & 3.56 \\
\hline Kia & 1 & 1.05 & Volkswagen & 5 & 7.08 \\
\hline
\end{tabular}

Our basic regression equation for estimating (and thus eliminating) impact of explicit car properties on price have a form:

$$
\begin{gathered}
\text { price }=\alpha+\beta_{1} \cdot \text { engine }+\beta_{2} \cdot f c o n+\beta_{3} \cdot \text { speed }+ \\
\beta_{4} \cdot \text { vers }+\beta_{5} \cdot A+\beta_{6} \cdot B+\beta_{7} \cdot C+\beta_{8} \cdot \text { ITA }+\beta_{9} \cdot N E W+ \\
\beta_{10} \cdot \text { MULTIFUEL }+u,
\end{gathered}
$$

Estimated results of this models are in Table 2. Error of estimated model meets all necessary requirements and we can conclude that this initial model without any corrections provides BLUE estimators. All explicit car properties together account for $93.5 \%$ of price variation thus implicit brand of a company just for $6.5 \%$ of leftover variation.

\begin{tabular}{|c|c|c|c|}
\hline variables & $\begin{array}{l}\text { Estimated } \\
\text { Coefficient }\end{array}$ & $V I F$ & $\begin{array}{c}\text { Estimated } \\
\text { Coefficient } \\
\text { (Standardised) }\end{array}$ \\
\hline constant & $-14428.5^{* *}$ & & \\
\hline speed & $210.2 * * *$ & 4.061 & 0.549 \\
\hline fcon & $-1346.2 * * *$ & 2.432 & -0.156 \\
\hline engine & $7.1 * * *$ & 2.954 & 0.281 \\
\hline vers & 10.5 & 1.446 & 0.040 \\
\hline A & $-7244.3 * * *$ & 5.111 & \\
\hline $\mathrm{B}$ & $-5784.5 * * *$ & 5.920 & \\
\hline $\mathrm{C}$ & $-3831.0 * * *$ & 2.829 & \\
\hline ITA & 1037.7 & 1.603 & \\
\hline NEW & -48.2 & 1.216 & \\
\hline MULTIFUEL & $-2902.6 * * *$ & 1.464 & \\
\hline \multicolumn{3}{|l|}{$\mathrm{n}$} & 50 \\
\hline \multicolumn{3}{|c|}{ Adjusted $\mathrm{R}^{2}$} & 0.935 \\
\hline \multicolumn{3}{|c|}{$\begin{array}{l}\mathrm{p} \text {-value of testing H0: relationship is } \\
\text { linear }\end{array}$} & 0.116 \\
\hline \multicolumn{3}{|c|}{$\begin{array}{l}\mathrm{p} \text {-value of testing H0: error is nor- } \\
\text { mally distributed }\end{array}$} & 0.755 \\
\hline \multicolumn{3}{|c|}{$\begin{array}{l}\text { p-value of testing } \mathrm{H} 0 \text { : heteroskedas- } \\
\text { ticity not present }\end{array}$} & 0.910 \\
\hline
\end{tabular}

Table 2. Regression model estimates and properties (Source: created by the authors)

Main insights we can draw at this part of analysis are (first of all we are concluding about the impact of the explicit properties on price and about direction of the impact, taking into account also the relative magnitude of the impact):

(i) Insights about quantitative properties of a car:

- We can say that the speed has the relatively biggest impact on the price so we conclude that the maximum speed that a car can reach influence the final price of the car mostly. This seems to be reasonable since the fastest cars are the one with the biggest engine in terms of power, in most of the cases, and these are also the one that belongs to the most expansive categories.

- We can say that fuel consumption has negative impact on car price: the most expansive cars are the less consuming ones. We can explain this by saying that probably the cars that consume less fuel are the one that are equipped with the newest and most innovative engines technologies that are therefore more expansive.

- Engine power has a positive impact on the price: the more power the engine has the higher is the price of the car. This seems to be obvious because more powerful engines are more expensive than small engines. 
- The number of versions for each model is not a statistically significant property.

(ii) Insights about qualitative properties of a car:

- Types of the vehicles are all statistically significant. We have $\operatorname{Cat} A, \operatorname{Cat} B, C a t C$ all referred to the CatD (that represent the biggest cars on the market) in the model. Cars of all these categories a cheaper than cars in CatD. We can conclude that the price is proportional to the size of the car. Cat $A$ that is the variable that represents the small cars is the one that has the highest price difference from cars in CatD: in-fact the smallest cars are also the cheapest one. $C a t B$ is relative to the utility cars (bigger than the one in $\operatorname{Cat} A$ ), and we have smaller price difference form cars in CatD: the utility cars, compared to the cars in the benchmark group, are cheaper but more expansive than the small cars. Lastly the coefficient on variable CatC (medium size cars) is still negative: these cars are cheaper than the car of CatD but more expensive than the car of the CatB.

- Multifuel cars are cheaper than those who do not have this property. The explanation of this is probably the fact that the there is a big gap between the majority of cheap engine fuel type (e.g. gasoline) and the small number of most expansive engine fuel (e.g. Diesel, LPG, Hybrid), so if a car is produced with different engines the "basic" gasoline versions would be on average cheaper than the similar cars produced just with one fuel engine.

- All the other variables are not statistically significant and we can conclude that Italian brands in Italy are not more appreciated than foreign brands, also new models are not more valuable than two or three years old ones.

We should note here that our finding do not conflict with Cantner et al. (2012) and Verboven (1996) who also analyzed car price factors.

Once we have the multiple linear regression model, we can use it to forecast prices and to make a comparison between actual prices and forecasted prices. In this way we can determine the level of competitiveness of the companies or at least of the different models (in case where company has just one model). In order to analyse the competitiveness of the brands we have to take a look at the difference between the real market price and the forecasted price. If the forecasted price is lower, it means that the company is selling cars at a price that is on average higher than the market price for similar cars.

Table 3. Evaluation of Company/Model Brand competitiveness (Source: created by the authors)

\begin{tabular}{|c|c|c|c|}
\hline \multicolumn{2}{|c|}{$\begin{array}{c}\text { High } \\
\text { brand competitiveness }\end{array}$} & \multicolumn{2}{|c|}{$\begin{array}{l}\text { Low } \\
\text { brand competitiveness }\end{array}$} \\
\hline Brand name & $\sum_{i=1}^{n} \hat{u}_{i} \cdot w_{i}$ & $\begin{array}{l}\text { Brand } \\
\text { name }\end{array}$ & $\sum_{i=1}^{n} \hat{u}_{i} \cdot w_{i}$ \\
\hline \multicolumn{4}{|c|}{ Company Level } \\
\hline Audi & 7.62 & $\begin{array}{r}\text { Alfa } \\
\text { Romeo }\end{array}$ & -4.39 \\
\hline Ford & 20.26 & Dacia & -48.90 \\
\hline Nissan & 19.81 & Fiat & -89.52 \\
\hline Opel & 2.59 & Hyundai & -2.97 \\
\hline Renault & 37.12 & $\begin{array}{r}\text { Mercedes } \\
\text { Benz }\end{array}$ & -7.42 \\
\hline Smart & 17.31 & Peugeot & -49.45 \\
\hline Volkswagen & 15.42 & Toyota & -18.16 \\
\hline \multicolumn{4}{|c|}{ Model Level } \\
\hline Mini Mini & 6.60 & \multirow{5}{*}{$\begin{array}{l}\text { Lancia } \\
\text { Ypsilon }\end{array}$} & \multirow{5}{*}{-41.31} \\
\hline $\begin{array}{r}\text { Kia } \\
\text { Sportage }\end{array}$ & 20.75 & & \\
\hline $\begin{array}{r}\text { Jeep } \\
\text { Renegade }\end{array}$ & 18.29 & & \\
\hline Citroen C3 & 23.46 & & \\
\hline $\begin{array}{r}\text { BMW } \\
\text { Series } 2\end{array}$ & 10.03 & & \\
\hline
\end{tabular}

According to the data that we have, in fact, all the companies are setting a price that sometimes is higher than the forecasted one and sometimes is lower, depending on the different models. We think that we can explain this by saying that the cars meet the customers need not only thanks to the technical characteristics but also because of others factors that are not easily measurable such as: fashion, history of the models, changes in society and human behaviours.

Nevertheless, we would like to highlight some tendencies that could be a starting point for further researches:

- First of all, 24 out of 50 models in our sample have a price that is higher than the forecasted.

- In the first 10 best-selling cars positions just 3 models have a price that is lower than the forecasted, this could suggest us that the customers are not that much concerned about the price nowadays. In fact, in the last 100 years we moved from a "production concept" marketing approach, in which people used to buy the cheaper 
product, to a "product concept" and a "marketing concept" approaches in which people prefer to buy products with higher quality and that best fit their needs.

- The "cult" models such as Fiat 500 are strongly overpriced: this means that the customers cares a lot about fashion and appearances, they are willing to pay more in order to have a car that is a cult and that can be noticed on the street.

- Some German medium size cars (e.g. BMW Series 2 and Audi A4) are strongly overpriced: perhaps because there are a lot of customers nowadays that are interested in high quality vehicles characterized by high reliability with a low fuel consumption and small enough to be easy to drive in the urban areas.

- Speaking about the results form Table 3 we can say that most of German brands are characterized by high brand competitiveness (Audi, Opel, Volkswagen) on the contrary the Italian brands have low brand competitiveness (Fiat has the lowest one).

- There is a big contrast between the two major French brands, Renault is a strongly competitive brand and Peugeot turns out to be one of the companies with lowest brand competitiveness.

\section{Conclusions}

Our aim was to create an instrument to evaluate the level of brands competitiveness of the companies qualitatively by using variables that can be measured in a quantitative way. For this reason, we adjusted basic linear regression analysis method to make it suitable for elimination of the product/service characteristics' value from its price and having leftover residual to evaluate qualitatively if the company is selling its brand products underpriced or overpriced. We think that this measure could be a suitable indicator of brand competitiveness when comparing companies in the same market. As we emphasized in literature review, there are many different methods to evaluate brand competitiveness and these methods are, in most of the cases, based on qualitative indicators that must be quantitatively evaluated. This is not simple to do also because each indicator could have a different weight. Using regression analysis as basis of our method, on the contrary, it is possible to evaluate which factor is statistically significant. Furthermore, it allows us to use data that are easy to find and that do not come from personal evalua- tion. We think that the proposed tool can be useful both for the company while evaluating their brand competitiveness and setting prices of new products and for the researchers to study the markets.

For practical application of our brand competitiveness evaluation model, we set an equation in which we included explicit properties of commodities and the implicit brand of the company (the random error in the regression model). Using this tool we can forecast the price and compare it with the actual one, thus we can understand if the product is over or under-priced and therefore the level of competitiveness of the brand.

In order to demonstrate how proposed analysis tool is working we decided to apply it to study the level of companies' brand competitiveness in the Italian car market. We chose ten characteristics of the cars and we estimated regression model using a sample of 50 car models. In our case the estimated regression model fits the data quite good and we found out that 7 out of 10 characteristics are statistically significant and account for $93 \%$ of price variation.

We think that our results are quite promising and this model could be applied to several fields, but there are also some issues. First, it may happen that in some fields the explicit properties of commodities are not as important as in our field. If we would try for instance to apply a similar model to the fashion industry it could be not as suitable as in our case, since here we have a big component of trend and fashion and the explicit properties weight less. Moreover, in some research fields it could be difficult to get data about characteristics that we want to consider or these characteristics could be not influential but that does not necessarily means that brand accounts for big part of price variation.

Starting from proposed brand competitiveness evaluation model, we can also try to suggest some improvements in the research process. We think that while implementing such a tool, one of the most important step is how to decide which explicit factors of commodities are important and should be included in the model. In this phase, several other tools can be used. We can for example get data from other customer satisfaction analysis or previous marketing researches, we can interview our customers asking which characteristics they are willing to pay for or we can ask experts of the product/service in the field to guess which the main properties to consider are. This preliminary phase is essential to create a model that fits the case in the best possible way. 


\section{References}

Adikaram, K. K. L. B.; Hussein, M. A.; Effenberger, M.; Becker, T. 2014. Outlier detection method in linear regression based on sum of arithmetic progression. The scientific world [online], [cited 04/03/2016]. Available from Internet: http://downloads.hindawi.com/journals/tswj/2014/ 821623.pdf

Baer, J.; Naslund, A. 2011. The NOW revolution: 7 shifts to make your business faster, smarter and more social. Wiley.

Biaowen, L. 2014. The evaluation research of corporate brand competitiveness in Web 2.0, The Open $C y$ bernetics \& Systemics Journal 8: 1074-1051.

Cameron, C. A.; Windmeijer, F. A. G.; Gramajo, H.; Cane, D. E.; Khosla, C. 1997. An R-squared measure of goodness of fit for some common nonlinear regression models, Journal of Econometrics 77(2): 1790-1806.

http://dx.doi.org/10.1016/s0304-4076(96)01818-0

Cantner, U.; Kruger, J. J.; Sollner, R. 2012. Product quality, product price, and share dynamics in the German compact car market, Industrial and Corporate Change 21(5): 1085-1115. http://dx.doi.org/10.1093/icc/dts002

Coates, T. T.; McDermott, C. M. 2002. An exploratory analysis of new competencies: a resource based view perspective, Journal of Operations Management 20(5): 435-450.

http://dx.doi.org/10.1016/S0272-6963(02)00023-2

Geller, L. 2012. Why a brand matters. Forbes/Enterpreneurs [online], [cited 04/03/2016]. Available from Internet:

http://www.forbes.com/sites/loisgeller/2012/05/23/ a-brand-is-a-specialized/\#85cfbe7504ad

Harrell, F. 2015. Regression modeling strategies. $2^{\text {nd }}$ ed. Springer International Publishing. http://dx.doi.org/10.1007/978-3-319-19425-7

Hoskisson, R.; Hitt, M.; Wan, W.; Yiu, D. 1999. Theory and research in strategic management: swings of a pendulum, Journal of Management 25: 417-456. http://dx.doi.org/10.1177/014920639902500307

Huang, Z.; Cai, L. A. 2015. Modeling consumer - based brand equity for multinational hotel brands - when hosts become guests, Tourism Management 46: 431-443. http://dx.doi.org/10.1016/j.tourman.2014.07.013

Kaufman, R. 2013. Heteroskedasticity in regression: detection and correction. SAGE Publications.

Kotler, P.; Keller, K. L. 1967. Marketing management: analysis, planing and control. Prentice-Hall.

Kumari, S. S. S. 2008. Multicollinearity: estimation and elimination, Journal of Contemporary Research in Management, January - March: 87-95.

Li, Q.; Liu, S.; Wang, X. 2013. Study on brand competitiveness model based on consumer's cognition: a case analysis, in Proceedings of 2013 International Symposium "International Marketing Science and Information Technology”, 13 July 2013, Guangxi, China.

Mansfield, E. R.; Helms, B. P. 1982. Detecting multicollinearity, The American Statistician 36(3.1): 158-160.

Mizik, N.; Jacobson, R. 2008. The financial value impact of perceptual brand attributes, Journal of Marketing Research 45(1): 15-32.

http://dx.doi.org/10.1509/jmkr.45.1.15

Nigel, H. 2005. Ten years of learning on how online advertising builds brands, Journal of Advertising Research 45(2): 255-268. http://dx.doi.org/10.1017/S0021849905050270

Razali, N.; Wah, Y. B. 2011. Power comparisons of Shapiro - Wilk, Kolmogorov - Smirnov, Lilliefors and Anderson - Darling tests, Journal of Statistical Modeling and Analytics 2(1): 21-33.

Saji, K. B.; Mishra, S. S. 2013. Investigating the role of firm resources and environmental variables in new product commercialization, Journal of Product \& Brand Management 22(1): 18-29. http://dx.doi.org/10.1108/10610421311298641

Sirikrai, S. B.; Tang J. C. S. 2006. Industrial competitiveness analysis: using the analytic hierarchy process, Journal of High Technology Management Research 17: 71-83. http://dx.doi.org/10.1016/j.hitech.2006.05.005

Uggla, H. 2014. Energy versus relevance in a comparative brand equity context: implications for brand portfolio management, IUP Journal of Brand Management 11(4): 29-39.

Verboven, F. 1996. International price discrimination in the European car market, The RAND Journal of Economics 27(2): 240-68. http://dx.doi.org/10.2307/2555925

Waldman, D. M. 1983. A note on algebraic equivalence of White's test and a variation of the Godfrey/Breusch - Pagan test for heteroscedasticity, Economics Letters 13(2-3): 197-200. http://dx.doi.org/10.1016/0165-1765(83)90085-X

Wang, H.; Jiang, J. 2008. Evaluation methodology of core competitiveness based on statistics of set occurrence, in The International Conference "Service Operations and Logistics, and Informatics IEEE/SOLI 2008”, 12-15 October 2008, Beijing, China.

Yohn, L. D. 2011. Competitive brand positioning. Blog: brand as business bites [online], [cited 04/03/2016]. Available from Internet: http://deniseleeyohn.com/bites-brand-yourbusiness-briefs/

Zhang, J.; Wang, S. 2015. An evaluation study of brand competitiveness of chain pharmacies based on the analytic hierarchy process, Asian Journal of Social Pharmacy 10(1): 35-42. 